\section{Epiphrenic diverticulum of the esophagus after peroral endoscopic myotomy}

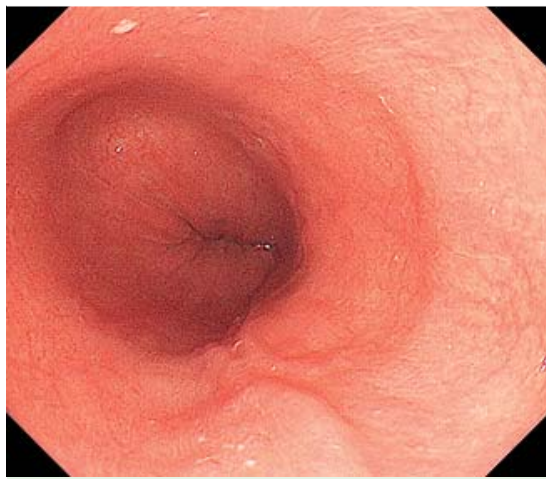

Fig. 1 Endoscopy shows a tight esophagogastric junction in a 34-year-old man with chest pain and dysphagia of 5 years' duration. The esophageal diverticulum could not be seen before peroral endoscopic myotomy.

A 34-year-old man was referred to our hospital because of chest pain and dysphagia that had lasted for 5 years. Endoscopy showed a tight esophagogastric junction ( Fig.1). On high resolution manometry (Star Medical, Tokyo, Japan), the mean lower esophageal sphincter (LES) pressure and integrated relaxation pressure were 44.3 and $43.3 \mathrm{mmHg}$, respectively ( $\bullet$ Fig. 2 ). Type II achalasia was diagnosed according to the Chicago classification criteria [1].

Peroral endoscopic myotomy (POEM) was successfully performed in the right anterolateral side of the esophagus, as previously described by Inoue et al. [2]. At the 2-month follow-up, hypercontractile peristalsis was seen, with a reduction of the LES pressure on high resolution manometry ( Fig.3). Additionally, an esophageal diverticulum had developed ( $\bullet$ Fig.4), although the patient's symptoms were markedly reduced; his preoperative Eckardt score of 7 had decreased to 0 postoperatively (a higher score indicates more pronounced symptoms) [3].

The formation of an esophageal diverticulum after POEM for achalasia has not previously been reported. The anterior and right sides of the lower esophagus are anatomically predisposed to the formation of diverticula [4]; thus, clinicians must pay careful attention when they use POEM to treat jackhammer esophagus [5]

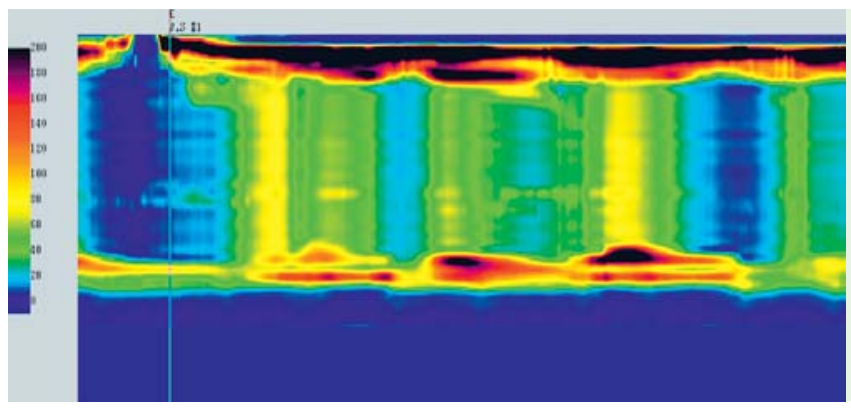

Fig.2 On high resolution manometry, the mean lower esophageal sphincter pressure and integrated relaxation pressure were 44.3 and $43.3 \mathrm{mmHg}$, respectively. Type II achalasia was diagnosed.

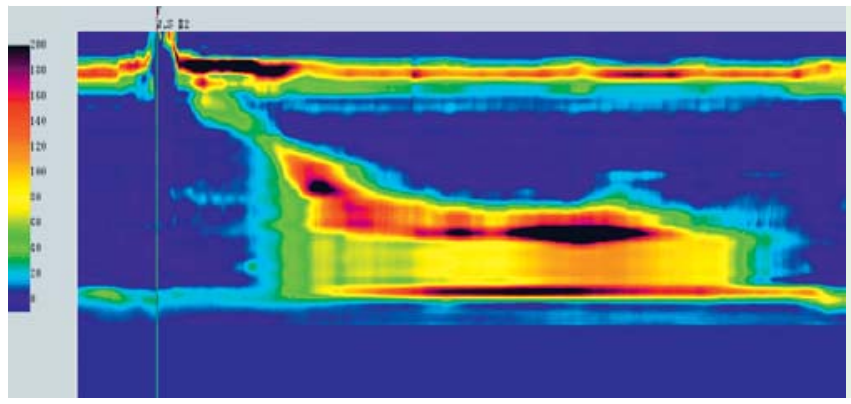

Fig.3 After peroral endoscopic myotomy, hypercontractile peristalsis was seen at the 2-month follow-up, with a reduction of the lower esophageal sphincter pressure on high resolution manometry.

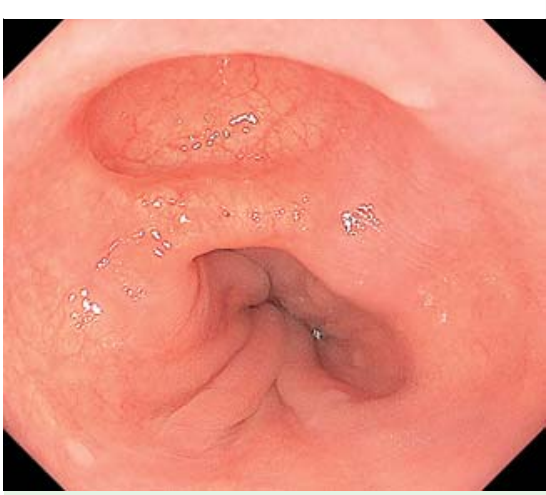

Fig.4 An epiphrenic diverticulum of the esophagus had developed on the anterior side.

or type II achalasia associated with complex pleural pan-pressurization, as in this patient. Posterior myotomy can be considered in such cases.

\section{Endoscopy_UCTN_Code_CPL_1AH_2AJ}

Competing interests: None

\section{Hiroki Sato, Kazuya Takahashi, Manabu Takeuchi, Yuichi Sato, Satoru Hashimoto, Kenichi Mizuno, Shuji Terai}

Division of Gastroenterology and Hepatology, Niigata University Medical and Dental Hospital, Niigata, Japan

\section{References}

1 Bredenoord AJ, Fox M, Kahrilas PJ et al. Chicago classification criteria of esophageal motility disorders defined in high resolution esophageal pressure topography. Neurogastroenterol Motil 2012; 24 (Suppl. 01): 57 65

2 Inoue $H$, Minami H, Kobayashi Yet al. Peroral endoscopic myotomy (POEM) for esophageal achalasia. Endoscopy 2010; 42: $265-$ 271

3 Eckardt VF. Clinical presentations and complications of achalasia. Gastrointest Endosc Clin N Am 2001; 11: 281 - 292

4 Soares R, Herbella FA, Prachand VN et al. Epiphrenic diverticulum of the esophagus. From pathophysiology to treatment. J Gastrointest Surg 2010; 14: 2009-2015 
5 Badillo R, Francis D, DeVault K. Formation of large esophageal diverticulum after peroral endoscopic myotomy. Gastrointest Endosc June 20. [Epub ahead of print]. DOI: 10.1016/j.gie.2015.05.020

\section{Bibliography}

Dol http://dx.doi.org/

10.1055/s-0034-1393232

Endoscopy 2015; 47: E509-E510

(C) Georg Thieme Verlag KG

Stuttgart · New York

ISSN 0013-726X
Corresponding author

\section{Hiroki Sato, MD, PhD}

Division of Gastroenterology

Niigata University Medical and Dental Hospital 757-1, Asahimachidori

Chuo-ku

Niigata City

Niigata 951-8510

Japan

Fax: +81-25-223-0776

pyloki@yahoo.co.jp 